\title{
EHMTI-0193. The impact of cognitive symptoms on migraine attack related disability
}

\author{
R Gil-Gouveia ${ }^{1 *}$, AG Oliveira², IP Martins ${ }^{3}$ \\ From 4th European Headache and Migraine Trust International Congress: EHMTIC 2014 \\ Copenhagen, Denmark. 18-21 September 2014
}

\section{Introduction}

The socio-economic impact of Migraine is related to work loss either by absenteeism or decreased work performance. Migraine associated cognitive dysfunction during an attack may be the cause of this difficulties.

\section{Aim}

To analyze the presence and relevance of cognitive symptoms during migraine attacks, relating their intensity and symptom related disability with other migraine defining symptoms.

\section{Methods}

Consecutive migraine patients of headache clinic fulfilled diaries scoring each migraine symptom (including cognitive symptoms) intensity and symptom related disability.

\section{Results}

One hundred consecutive patients were included in this study (eight males, age average $31.2 \pm 7.5$ years), 34 (all females, age average $31.8 \pm 8.8$ years) returned information on 229 attacks, on average 6.7 per participant. This population had a moderate to severe impact of migraine (HIT$663.4 \pm 4.4)$. Intensity of each symptom is always rated slightly higher than disability. Pain is the symptom scored with the highest intensity and disability, followed by cognitive symptoms (difficulty in thinking and worsening with mental effort) and photo and phonophobia.

\section{Conclusions}

Cognitive symptoms are frequent during migraine attacks, their intensity and perceived symptom-related disability is second only to pain, during the attack. New acute migraine drugs trial should include cognitive evaluation as

${ }^{1}$ Headache Center, Hospital da Luz, Lisboa, Portugal

Full list of author information is available at the end of the article a secondary end-point, in order to be able to diminish decreased work performance and Migraine burden.

No conflict of interest.

\section{Authors' details}

'Headache Center, Hospital da Luz, Lisboa, Portugal. '2Pharmacy Department, Universidade Federal do Rio Grande do Norte, Rio Grande do Norte, Brazil.

${ }^{3}$ Department of Clinical Neurosciences, Instituto de Medicina Molecular

(IMM) Faculdade de Medicina Universidade de Lisboa, Lisboa, Portugal.

Published: 18 September 2014

doi:10.1186/1129-2377-15-S1-D21

Cite this article as: Gil-Gouveia et al:: EHMTI-0193. The impact of

cognitive symptoms on migraine attack related disability. The Journal of Headache and Pain 2014 15(Suppl 1):D21.

\section{SpringerOpen ${ }^{\odot}$}

(c) 2014 Gil-Gouveia et al; licensee Springer. This is an Open Access article distributed under the terms of the Creative Commons Attribution License (http://creativecommons.org/licenses/by/2.0), which permits unrestricted use, distribution, and reproduction in any medium, provided the original work is properly cited.
Submit your manuscript to a SpringerOpen ${ }^{\circ}$ journal and benefit from:

- Convenient online submission

- Rigorous peer review

- Immediate publication on acceptance

- Open access: articles freely available online

- High visibility within the field

- Retaining the copyright to your article

Submit your next manuscript at $>$ springeropen.com 